\title{
The politics of post-qualitative inquiry: history and power
}

\begin{abstract}
In this paper we offer a critical reading of the increasingly popular 'postqualitative' approach to research. We draw on insights from postcolonial theory to offer some provocations about the methodological and conceptual claims made by post-qualitative inquiry. The paper considers how post-qualitative inquiry opens up possibilities for post-humanist social research. But our critical reading of these 'new' approaches argues that such research needs to attend to political and historical relations of social power, both in the worlds it constitutes and in the processes of its knowledge production. Without explicit attention to power and history, the (non)representational logics of post-qualitative inquiry risk operating less as 'new' mechanisms for generative and subversive posthumanist research and more as processes of closure and erasure: closedoff from the worlds and people being researched.
\end{abstract}

Keywords: post-qualitative inquiry; postcolonial theory; qualitative research; methodology; politics

\section{Introduction}

Post-qualitative inquiry has emerged in recent years as a new methodological movement situated within the much broader new materialist and ontological 'turn' (see St Pierre, 2014:2). In this paper, we draw on insights from postcolonial theory to offer some provocations about the methodological and conceptual claims made by key proponents of post-qualitative inquiry (e.g. Lather 2013; Maclure 2013; St Pierre 2013). In doing so, we arrive at this conversation with some slightly different theoretical tools to those used within post-qualitative inquiry. We are, in other words, 'outsiders' to this emergent field and in the first section of this article we explore what standing on the edge of this methodological movement allows us to see. Yet, in many ways we consider 
ourselves engaging very much in a conversation premised on a range of shared starting points, as explored further below. Indeed, in writing this response, we find ourselves critically engaging with scholars and researchers who influenced our own research pathways. Feminist debates surrounding research knowledge and methodology, for instance, have been formative for us as researchers, including the work of many now within post-qualitative inquiry. Therefore, our motivation here is first and foremost driven by a desire to engage in open constructive conversation with others also grappling with issues of power, representation, methodology, and the pressured environment of research governance and practice. This paper is not, therefore, an analysis of new materialism or the ontological turn broadly, or of Deleuze and Guattari or Barad, for example. Rather, it is an interpretation of how we, as relative outsiders, see the potential effects of the positions taken within the particular orientation of post-qualitative inquiry.

In this paper, we start with an exploration of the ways in which postqualitative inquiry orients itself, and outline what we understand as shared starting points of engagement. Following this, we take up three issues to explore in more detail. First, we unpack some of the boundary politics of post-qualitative inquiry: its project to interrogate humanism, representation, data, feminist qualitative research, neoliberal governance. We consider how such an interrogation creates both possibilities and closures, and we draw attention to some of the boundary-maintenance that the stated openness and amorphousness of post-qualitative inquiry can otherwise obscure. Second, we examine the post-qualitative heralding of the 'new'. Here we suggest there are 
opportunities within post-qualitative inquiry to engage more seriously with temporal dimensions of social experience, including historical perspectives. Building on this discussion, third, we consider the place of power and politics in post-qualitative research. We ask in particular for clarification about how postqualitative inquiry engages with ethical and political questions of researching marginalization and oppression in the context of global inequalities and hierarchies of knowledge.

\section{Approaching post-qualitative inquiry}

In an influential text that pre-dates the post-qualitative emergence, but that is clearly connected and significant to the post-qualitative project, St Pierre and Pillow warn that there are many dangers in rigid and unproblematised mobilisations of subject-object positions within the knowledge created by research (2000:4-5). Power pervades the creation of particular subjects, and the creation of these subjects has powerful effects. These are 'dividing practices', as Foucault (1994: 326) terms it. Historically contingent operations and techniques of power that form subject positions also discipline, surveil, and produce the forms of conduct for such subjections (see Foucault, 1994). For St Pierre and Pillow, the place of subjectification within research causes a fundamental - and irreparable - fissure in qualitative humanist research practice. They ask, 'If humanism's inscription of reality, knowledge, truth, rationality, and the subject are dangerous fictions, then its 'science' also becomes problematic. If this is the case, what might a different science look like?' (St Pierre \& Pillow, 2000: 10). 
This question is at the centre of the subsequent growing collection of research coming under the umbrella of 'post-qualitative inquiry'. Whilst clearly diverse, there are some commonalities that stretch across the developing body of post-qualitative literature. Principally, these commonalities are based on its epistemological/ontological stance: post-qualitative inquiry firmly delineates its approach as being after (or against) a so-called reification of the human in humanist research, and thus firmly within 'new materialism', 'new empiricism', and the 'ontological turn' (St Pierre, 2013). These broader new materialist and ontological turns are characterised by a diverse range of scholarly engagements. In explicitly labelling itself as 'post-qualitative', rather than a new materialist or ontological methodology, post-qualitative inquiry is an embedded, but distinct, orientation within this broad field. This particular line of work has been represented by, for example, a number of recent edited collections, a journal special issue, and articles and scholars drawing on the explicit terminology of 'post-qualitative': it is this specific set of literature with which we engage here (e.g. Lather \& St Pierre, 2013; St Pierre, 2014; Maclure, 2013; Lather, 2013).

Our reading into this line of research began with what could be understood as the boundary-setting texts of the post-qualitative project, for example, Lather \& St Pierre's (2013) edited journal special issue entitled PostQualitative Research and St Pierre's personal reflection on the history and emergence of post-qualitative inquiry (2014). We learn from this literature that the motivation to develop a post-qualitative methodology is driven, in part, by what is viewed as the institutionalisation, standardisation and 'scientification' of feminist qualitative research. Post-qualitative researchers have pointed 
specifically to the 2002 Scientific Principles for Education Research in the United States as a formative event in the development of post-qualitative inquiry. These principles are viewed as illustrative of the co-option of feminist qualitative research into palatable, mainstream and positivist paradigms (Lather \& St Pierre, 2013; St Pierre, 2014). Patti Lather, for instance, suggests there is mounting pressure for qualitative research to 'provide better evidentiary warrants' thereby reducing qualitative research to an instrument of neoliberal policy imperatives (2013: 636). Consequently, it is suggested that the methodological developments made by feminist qualitative researchers in the 1990s, for example, have become co-opted within problematic science-based research governance measurement mechanisms. In this sense, post-qualitative inquirers have identified themselves as 'working the ruins' of feminist qualitative research (St Pierre \& Pillow, 2000).

To be sure, the push for evidence and scientific verification can remobilise taken-for-granted subjectifications and epistemological orders. It is certainly generative and necessary to ask, as Deleuze does, 'How must it be in order to say that? Which manner of Being does this imply?' (Deleuze, 1980 in Davies et al, 2013: 659). As scholars also interested in research that critically engages with the operations of power, we are acutely aware of the ways in which research knowledge across the sciences and social sciences - past and present actively contributes to producing, objectivizing, measuring and comparing particular subjects. We share, for instance, a concern to develop research agendas that unthread - and hopefully unsettle - the 'research subject' that is tightly (and often unthinkingly) woven into much of the evidence-based research 
imperatives of neoliberal interpretations of 'best practice' (see Brown, 2015): the rational, independent, value-accruing, lifelong learning, entrepreneurial, striving subject. For instance, the cautions against reifying 'authentic voice' within ethnographic research and the presumption that researchers have the authority to 'tell it like it is', are useful and necessary prompts to reflect upon the presumed authority of researchers, methods and methodologies and the sorts of knowledge research produces (see Lather, 2002; St Pierre, 2008). Thus, we are genuinely interested in the assertion that post-qualitative inquiry is 'working the ruins' of feminist qualitative research. With this motivation, we consider more closely the affordances, limitations and contingencies of post-qualitative inquiry; its boundary politics.

\section{The boundary politics of post-qualitative inquiry}

One of post-qualitative inquiry's leading proponents, Elizabeth St Pierre, states that 'In 2011, I deliberately used the rather large and ambiguous term "post qualitative" to mark what I see as the impossibility of an intersection between conventional humanist qualitative methodology and "the posts"' (2014: 3). At the heart of St Pierre's disillusionment with the possibilities of the 'conventional humanist qualitative research process' appears to be an irresolvable theoretical clash (St Pierre, 2014: 3). She warns that she is 'not rejecting conventional humanist qualitative methodology' but that she cannot accept it as she does not accept 'its humanist assumptions' (2014: 4). While St Pierre leaves open the possibilities for post-qualitative inquiry, she outlines two elements that she believes are important in progressing post-qualitative methodology. First, the 
use of productive analyses from the 'posts' theoretical canon, including for example, 'archaeology' and 'genealogy' from Foucault, 'rhizoanalysis' and 'schizoanalysis' from Deleuze and Guattari, 'affirmative deconstruction' from Derrida and 'paralogy' from Lyotard (2014:3). And second, an engagement with the ontological, 'too often ignored in the rage for meaning that centers the Cartesian knowledge projects privileged in the academy' (2014: 3).

Thus, explorations in post-qualitative inquiry explicitly seek to create conceptual and methodological pathways that reject the presumptive centring of the human subject. As such, research in this space has sought to rethink the constitution of 'data' (St Pierre, 2013, Jackson 2013), the 'interview' (Honan, 2014; Mazzei, 2013), 'representation' (MacLure, 2013), and other normative methodological categories of social sciences as a way of pushing back against the rigid forms of research recognised as scientific. Through these interrogations, by 'looking awry' at the production of knowledge, post-qualitative inquiry sets out to 'open the future up to possibilities' (Lather \& St Pierre, 2013: 629). According to St Pierre and Pillow, the projects of the 'posts' (poststructuralism, postcolonialism, among other lines of inquiry that often get grouped here) offer 'opportunities for limit-work, work that operates at the boundaries of the possibilities of humanism' (2000: 6). Proposals for post-qualitative inquiry suggest that its intention is not to form a new regime of truth, and that it is not driven by an assumption 'that humanism is an error that must be replaced' (ibid: $6)$.

Yet, post-qualitative inquirers buttress their contributions by creating a boundary between humanism and their refusal of it. In other words, post- 
qualitative inquiry (perhaps inadvertently) appears to establish itself as humanism's Other, defined always in relation to what it is not. For instance, in their introduction to the journal special issue on post-qualitative inquiry Lather and St Pierre (2013) posit that the big, risky, question for research methodology lies in the new materialist challenge to human/non-human binaries. They suggest that those working in and with post-qualitative inquiry demonstrate the limits of humanism 'as we put "post" ontology to work' (2013: 631). Similarly, Jackson (2013) suggests humanism, and the qualitative research associated with it, relies on essentialist forms of methodology and knowledge. She writes, "traditional" qualitative data analysis mirrors the assumption in humanism that there are universal, abstract, structural characteristics that are foundational for grouping, structuring, naming, and categorizing' (2013: 742). Post-qualitative inquiry, it is suggested, offers an alternative to this 'grid of regularity' (St Pierre \& Pillow, 2000: 6).

This act of boundary formation signifies that post-qualitative inquiry is something, though an explanation of its form, criteria, constitution, and contingency seems to be avoided in an effort to escape what are understood as the negative representational logics of humanism. Reading closely and with effort, as we are asked to do (St Pierre, 2013: 6), offers some insights into the shape post-qualitative inquiry has taken so far. Of course, we recognise that, like humanism, post-qualitative inquiry is not a singular entity and has multiple sources, connections, and possibilities. However, we can identify its emergent foundational theoretical canon (Barad, Butler, Deleuze and Guattari, Pickering), its connection to broader projects of new materialism and post-human research, 
as well as a set of common goals: the pursuit of unpredictability, materiality and movement that might defy or speak back to a rigid humanist essentialism that is strongly manifest in the dominance of neo-positivist scientific principles and discourses of 'evidence-based' research. Such pursuits often lead, perhaps unwittingly, to dense theorisations that are extremely difficult to untangle. For those outside the post-qualitative discourse community, like us and presumably the participants of their research, it is hard not to find such a densely theoretically-led approach bewildering, and perhaps even 'exhausting' (see Reay, 2015).

Our point here is that whilst post-qualitative inquiry draws upon an identified 'opening' in the rejection of the purported essentialisms and determinisms contained within humanism, it inevitably creates its own boundaries. In articulating itself as humanism's Other - or 'after' (see Lather, 2013) - and drawing on a distinct set of theoretical and discursive resources to do so, the post-qualitative project produces its own set of methodological and conceptual closures. It is not the potential closures in and of themselves that are of primary concern to us (arguably all academic 'turns' produce boundaries and closures), but how their contingencies and consequences may be obscured through a set of discursive mobilisations within post-qualitative commentary. Indeed, we are not advocating an anti-theory stance, and nor are we shying away from conceptual complexity or the possibilities such complexities afford. Rather we suggest the need for closer explication of the uses and roles of theorisations, conceptualisations, and discursive tools, in the sorts of claims we make in research. As Said $(2004,14)$ reflected on the function and form of the 
humanities, there is a danger that the humanities will become 'a whole factory of word-spinning [...], that in their jargon and special pleading address only likeminded people, acolytes, and other academics', effectively detouring research from 'its rightful concern with the critical investigation of values, history and freedom'.

The discursive mobilisations of post-qualitative inquiry, we argue, obfuscate the power of methodological resources and actors; power that must be understood in relation to the global political economy of academic labour and knowledge production. There are, for instance, practices of boundary creation at work in post-qualitative inquiry, through the use of particular theorisations and language, which exclude some as much as it may create an opening for others. This works both discursively (i.e. who feels theoretically astute enough to participate), and materially. For example, the call for research not 'to over-attend to external pressures and developments' (Lather and St Pierre, 2013: 629) has very different possibilities for academics who have tenured and high-status positions and those who do not. We note here the numerous material resources underpinning the production of academic knowledge which filters those who are able to speak legitimately for the field. ${ }^{1}$

The moves of boundary formation and maintenance do a particular kind of work within academic communities. Expert communities regulate what is inside and outside the post-qualitative domain yet they are able to make appeals to unpredictability, openness, and inclusion. However open and democratic we would like to think our academic endeavours are, the sponsorship of certain

\footnotetext{
1 This includes, for instance, the effects of a corporatized publishing industry and the growing turn towards the requirement of fees for paper submission and publication, as in this journal.
} 
ideas, by certain people, in certain geopolitical and institutional contexts, carries more legitimacy than others: these, we urge, are the global politics of knowledge production that the post-qualitative project needs to attend to rather than simply reject (see Canagarajah, 2002; Connell, 2007). The post-qualitative project, we argue, papers over its 'own implication in intellectual and economic history', as Spivak has long noted of poststructural forms of reconstruction that do not address postcolonial conditions of inequality (Spivak, 1988: 6). The mystification of its form and contingencies may enable proponents of postqualitative inquiry to bypass the broader ethical and political implications of their work.

\section{The colonial temporal logics of the 'new'}

In another 'outsider's response' published as a part of a special journal issue on post-qualitative inquiry, Jennifer C. Greene notes a post-qualitative 'infatuation with "the new"' (2013: 754). Reflecting on this, Greene expresses concern that the post-qualitative focus on the 'new' fails to connect 'now' to the past and honour the 'parts of the past that should endure' (2013: 754). In response, Greene proposes there is something to be gained from nurturing a sense of continuity and connection to history in relation to acting in and making sense of the world as researchers. Undoubtedly, Greene points to a significant trend within the post-qualitative inquiry literature. One of the primary ideas underpinning the demarcation of the post-qualitative project is a conceptual focus on, and analytic use of, the 'new'. The logics of the 'posts' mobilised in post- 
qualitative inquiry, in other words, are premised on the authority of and need for newness (see also Ahmed, 2008).

There is some acknowledgement that the (supposed new) focus on ontological concerns in post-qualitative inquiry is perhaps a revisiting of something that has been considered in the past, with St Pierre suggesting it may be seen as a 'return' (2014: 14, original emphasis). This important point, however, is briefly engaged and is overshadowed by a broader emphasis on the 'new'. Lather (2013: 638-9), for instance, suggests a 'new methodology for new times' and draws on Deleuze to affirm a research approach in which 'Data get lived in new ways'. For Lather (ibid: 642) post-qualitative inquiry is:

... a new culture of method of breaking methodological routine by savoring our critical edges, aporias, and discontents. It troubles visibility and holds up blind spots as productive sites toward "the risk of a new relationality" (Berlant in Davis \& Sarlin, 2008).

Here, Lather suggests old Western binary thinking is disrupted in favour of 'new animism, a new materialism, and a new vitalism toward new possible destinies' (ibid: 641). Similarly, St Pierre states her preoccupation with 'a new ontology, the new materialism, and the new empiricism' (2013: 653), while MacLure notes the common criticisms of the 'linguistic turn' by new materialism, linking this newness to a refusal by the data to render meaning (2013: 659).

With Greene, we also suggest the need to critically reflect on the effects of heralding 'the new': new concepts, new materialisms, new empiricism, new ontologies, new century. The proclamation of the 'new' is not merely descriptive; it does analytic and conceptual work. As Stuart Hall (1996) identified in his exploration of the 'New Times' proclaimed in the late 1980s, the proclamation of 
the 'new' is both an attempt to grapple with fast-changing social, economic and cultural transformations, and an analytic category carrying its own effects. In the context of post-qualitative inquiry, we suggest there is a temporal disjuncture and logic created in the repeated emphasis on the possibilities of the 'new', placed in contradistinction to the limitations of the (humanist) 'old'.

In large part, the focus in post-qualitative inquiry to explore the 'new' appears to be connected to the urge to refuse the 'scientification' of humanist qualitative research. For example, Lather and St Pierre question the representational logic and 'neo-positivist upsurge' of 'big data' and 'metric mania' (2013: 629-30); MacLure interrogates the 'hierarchical logic of representation' (2013: 658); and St Pierre suggests that positivist social science methodology idealises and normalizes 'a particular form of science that equates knowledge with science' (2013: 654, original emphasis). In response, post-qualitative researchers aim to render 'the categories of humanist qualitative research problematic' (Lather \& St Pierre, 2013: 630). Here, the 'new' is positioned as offering foundational possibilities for such a project. MacLure suggests 'the new materialisms work across boundaries of science and the social, nature and culture' (2013: 659). St Pierre advocates 'refusing that binary logic that pervades our language and thus our living' (2013: 655), while Lather calls for methodologies that resist 'stasis and capture, hierarchy and totality' (2013: 635).

Of course, research practices and academic institutions have long been bound to problematic knowledge productions and assumptions and practices of governance. For example, postcolonial scholars have questioned the ways in which knowledge and institutional practices are linked to the colonizing project 
of racial categorisation and division (e.g. Fanon, 1966: 51-2). More recently, Tuck and Yang (2014) discuss how research in settler colonial contexts can operate as 'inquiry as invasion'. They write (2014: 812),

The academic codes that govern research, human subject protocols, and publishing already territorialize knowledge as property and researchers as claimstakers. Academic codes decide what stories are civilized (intellectual property) and what stories are natural, wild, and thus claimable under the doctrine of discovery.

There are clear connections between the postcolonial critique of research knowledge and the concerns of post-qualitative inquiry. Authors note the challenges of what they term 'the new' being recolonized by 'positivisms' (Lather 2013: 637) and recognise that 'tradition' is brought 'with us into the new' (Lather \& St Pierre, 2013: 630). Indeed, as St Pierre and Pillow assert 'we are always speaking within the language of humanism, our mother tongue' (St Pierre \& Pillow, 2000: 4).

Despite these assertions, as we have examined above, post-qualitative inquiry firmly positions itself as humanism's Other, and draws on the discourse of the 'new' to do so. This privileging of the 'new' at the expense of the 'old' could have the effect of reinforcing a colonial logic based on the separation of the mind and the body (see Tuck \& McKenzie, 2015). While attempting to advocate greater engagement with issues of ontology in post-qualitative inquiry (e.g. Lather \& St Pierre, 2013; MacLure, 2013; St Pierre, 2013) the ontological can appear as though it is in binary opposition to epistemology, thereby reinforcing the mind/body dichotomy. Sara Ahmed makes a similar claim in her critical 
reflection on the theoretical work being undertaken in the name of new materialism. She writes (2008: 35):

I would argue that the very claim that matter is missing can actually work to reify matter as if it could be an object that is absent or present. By turning matter into an object or theoretical category, in this way, the new materialism reintroduces the binarism between materiality and culture that much work in science studies has helped to challenge.

Moreover, in the search for a 'break' from the old, post-qualitative inquiry may reiterate a modernist-colonial impulse in which progress is positioned along a development trajectory of linear time. Lather, for instance outlines the iterative development of post-qualitative inquiry in a number of moves: QUAL 1.0, QUAL 2.0, QUAL 3.0 and now QUAL 4.0. - post-qualitative inquiry (2013: 634-5). The latest progression, QUAL 4.0, 'is becoming in the Deleuzian sense as researchers who, weary of a decade of defending qualitative research and eager to get on with their work, again imagine and accomplish an inquiry that might produce different knowledge and produce knowledge differently' (2013: 635). In distinction, QUAL 1.0 is 'conventional interpretive inquiry that emerged from the liberal humanism of sociology and cultural anthropology with a fairly untroubled focus on standpoint epistemologies, a humanist subject who has an authentic voice, transparent descriptions of lived experiences, and the generally untroubled belief that better methods and richer descriptions can get closer to the truth' (ibid).

The danger here is twofold. First, the proclamation and focus on the 'new' eschews persisting colonial knowledge practices in research. The enthusiastic embrace of the 'new' by post-qualitative inquirers is such that it may echo the 
'poetics of Empire: to discover, to chart new terrain, to seek new frontiers, to explore' (Tuck \& Yang, 2014: 813). The strong focus on the 'new' occurs at the expense of an understanding of the past in relationship with the present and future. As Aileen Moreton-Robinson observes of the settler colonial Australian context: 'Indigenous people's position within the nation-state is not one where colonizing power relations have been discontinued' (2015: 18). The same could be said of the academy, in which we must continue to attend to the colonizing effects of research on 'Indigenous, ghettoized, and Orientalized communities' (Tuck \& Yang 2014: 811; see also Smith, 2012, Moreton-Robinson, 2011). By leaving colonial practices untouched analytically, the logics of colonialism remain unrecognized and unproblematized in (qualitative) research methodology, whether QUAL 1.0 or the 'new' QUAL 4.0.

Second, and relatedly, the paradoxical positioning of the 'new' on a linear trajectory (from QUAL 1.0 to 4.0) that moves further away from the 'troubles' of humanism, may embed a modernist-colonial impulse within QUAL 4.0. Postqualitative inquiry is now able to state itself as being more progressed and progressive than earlier or other ways of knowing. Indeed, the post-qualitative rendering of humanism - as solely concerned with evoking a stable categorical subject - eclipses a much messier, diverse, and contested intellectual genealogy of humanism. Here, humanism and feminist qualitative research is positioned as the problematic past, whilst the myriad 'posts' and 'news' are heralded as arenas for possibility. This works to position what comes before post-qualitative inquiry as 'forgetful', to borrow from Ahmed (2008), of its objects of concern (materiality, multiplicity, messiness, ontology), and thus creates unnecessary caricature of humanism and its many contestations and varieties. As a result, post-qualitative 
inquiry is in danger of forgetting the many struggles over knowledge and (mis)(re)presentations that have come before it, and which also have attempted to address issues of multiplicity, uncertainness, affect, ontology and materiality. As Ahmed writes on new materialism's interpretation of feminism (2008: 32), the narrative of 'forgetful feminism' involves constructing a particular version of feminism's histories that itself 'forgets' significant feminist contributions on the ontological, material and biological.

To confront and resist the power of language, research and knowledge acquisition to colonise requires, Tuck and Yang assert (2014: 815), 'refusing thoroughly', not just through stated refusal but active refusal:

Because settler colonial invasion is active, and the imperative to invade is unrelenting, a refusal stance against inquiry as invasion requires more than passive resistance, more than simply not selling/telling.

The 'new' in post-qualitative inquiry is a refusal of the 'humanist old'. This is, undoubtedly, an attempt to move beyond the problematic power dynamics of subjectification within qualitative research. However, rather than simply moving on and beyond, we suggest the need for deep engagement with the traditions of the past, and their continuing effects. As Ann Stoler (2008: 203) urges, it is within the slippage between seemingly opposing things that political understanding can be garnered:

In thinking about imperial debris and ruin one is struck by how intuitively evocative and elusive such effects are, how easy it is to slip between metaphor and material object, between infrastructure and imagery, between remnants of matter and mind. The point of critical analysis is not to look "underneath" or "beyond" that slippage but to understand what work that slippage does and the political traffic it harbors. 
So while Greene suggests, perhaps with some nostalgia, in her 'outsiders response' that it is important to honour the 'parts of the past that should endure' (2013: 754), we suggest there is a more pressing political imperative to honour, see, understand and at times embrace while at other times contest: the parts of the past that $d o$ endure.

\section{Power, politics and ethics in post-qualitative inquiry}

As discussed above, one of the primary reasons we are drawn to read, and engage in, the emergent post-qualitative inquiry literature is what we understand as a shared concern to examine, critique and challenge the often taken-for-granted structures of power that permeate research practices and priorities. As noted, the history of research and research institutions is by no means one of virtuous honour. Academic research has been - and continues to be - embroiled in divisive and problematic practices of subjectification. The history of the social sciences is framed by a research inclination to describe, measure, define, categorise, and explain sociological and cultural 'difference'. Scientific 'discoveries' and 'certainties' included, for instance, women's inclination to hysteria and activities within the private sphere, whilst the majority South have been perpetually described in terms of absence: an absence of culture, of intelligence, of civilisation, of capability (see Sherwood, 2001; Simpson, M., 2007).

These, however, are not simply past practices to be written into selfcongratulatory histories of academic progress. Assumptions of colonial, class, 
heterosexual and masculine righteousness are unfortunately not bygone tales: their effects and practices continue today. Of particular significance are the continuing difficulties and tensions that lie in the research of oppression, disadvantage, poverty and difference. So often, research does little to challenge or alter problematic portrayals of victimhood and deficit and the taken-forgranted political and social norms that perpetuate such portrayals (see Peel, 2003; Farrugia \& Gerrard, 2016). Indeed, research focus on the apparent disadvantaged, dysfunctional or different 'Other' can fuel the dangerous fantasy that the 'objectivity' of structural oppression can be found in documenting the lives of Others (see Tuck \& Yang, 2014). It is important to recognise the function of this kind of research as a type of academic currency or capital, demonstrating research authenticity for researchers within a hierarchical field of knowledge structured by colonial power. As Tuck and Yang assert, "The stories that are considered most compelling, considered most authentic in social science research are stories of pain and humiliation' (2014: 812). This illustrates the ongoing impact of 'colonizing societal conditions on interpersonal relationships', even in contexts in which such conditions are the focus of critical attention (Land, 2015: 9).

In this way, with post-qualitative inquiry, we share a concern with how qualitative research is increasingly made 'scientific' and 'objective'. It does appear that as qualitative research is made to mould itself into the rules and codes of traditional scientific research, 'data', 'coding', and 'fieldwork' become understood as stable taken-for-granted and mechanical research practices. 'Coding', Tuck and Yang suggest - and drawing on St Pierre and Pillow - 'has 
already surrendered to a theory of knowledge.' The question then becomes, '...what is the code that lies beneath the code?' (2014: 811). Thus, at the centre of post-qualitative inquiry is scepticism of the inscriptions and prescriptions of 'data', 'coding', 'fieldwork' and the types of 'representations' and claims to knowledge made in their name. Data is not an 'inert and indifferent mass waiting to be in/formed and calibrated by our analytic acumen or our coding systems' MacLure argues (2013: 660). 'We [researchers] are no longer autonomous agents, choosing and disposing' (ibid).

At the heart of this scepticism is the post-qualitative materialist, ontological and post-humanist 'turn', which calls into question the authority of the researcher, humanist epistemology and the authority of research. This has clear links to, for instance, Lather's earlier work to foreground problematic presumptions of authority and truth, linked to representational logics of 'consumerism and voyeurism' in her and Smithies' 1997 Troubling the Angels (Lather, 2001: 207; Lather and Smithies, 1997). More recently, within postqualitative inquiry, Lather and St Pierre focus on the problematic of 'data', and the assumption within ethnographic qualitative research that 'the human is superior to and separate from the material' (2013: 629). Therefore, postqualitative inquiry challenges the authority of research that searches for 'truth' and 'authenticity' in the experience of others. The current imperative, MacLure (2013) suggests, is to completely rethink what research is, and the knowledge it creates. Here, she troubles much of the taken-for-granted research practices within qualitative research: 'wise judgements' based on themes and codes, and the 'reading' of participants as being 'angels' of insight (ibid). 
Our concern with this is not the embrace or exploration of alternative ways of understanding sociology, ethnography, qualitative and academic research. Rather, our concern is in how much of the post-qualitative inquiry still includes human 'subjects' within the research, but seems to obfuscate important political and ethical considerations surrounding the claims made about these people. In other words, the methodological and conceptual space created by post-qualitative inquiry appears preoccupied with research products and practices - data, fieldwork, interview transcripts - and not the women, men and children who are the basis of these research products; the people who gave their time, and allowed the researchers to witness, participate, and be involved in their lives.

Indeed, much of the post-qualitative reflection on humanist research, in the 'ruins' of feminist ethnography, centres on problematics pertaining to the researcher-self: what to do with 'data', how to define 'data' (if it exists), what to do with transcripts, how to understand fieldwork. Here routinized and overly prescriptive applications of qualitative coding and analysis are problematized by exploration of the material and the researcher's affective and visceral reactions to research (e.g. MacLure, 2013). Reflections on the uncertainty of data, and the claims that can be made from it, poses a particular challenge for post-qualitative inquirers: how can one make, or claim to make, representations of Others? Drawing on Deleuze, MacLure puts it this way: 'Representation serves the 'dogmatic image of thought' as that which categorises and judges the world through the administration of good sense and common sense, dispensed by the autonomous, rational and well-intentioned individual, according to the 
principals of truth and error' (2013: 659). Importantly, MacLure is not suggesting that representation does not occur, but that new materialism causes a fundamental rupture in the 'business as usual' qualitative research representation, which presumes the responsible autonomous human (ibid). Representation is problematized through a post-humanist lens, which rejects the subject and subjectification as the basis of knowing or of research (see also Thrift, 2008).

These explorations respond to important issues surrounding what it is to understand and know, and the place of researcher intuition and politics in research. Post-qualitative inquiry wishes to throw open the basis of all these research practices: methods, methodology and the claim to know. There are undoubtedly significant, and worrying, repercussions in the now global embrace of statistical 'proof' and other numerical verification tools in the kinds of knowledge valued and created. The envelopment of qualitative research into the matrix of 'scientific' verification, what is 'counted' as research - and what is funded - fundamentally alters its epistemological basis. In other words, the performative tools of research governance have effects. We welcome problematizations of such contemporary regimes of research truth.

However, the approach and focus taken by post-qualitative inquiry, for us, raises two principal tensions. First, we have a concern that the rejection of, and turn away from, contemporary debates surrounding the claim to know, and concurrent turn towards researcher intuition and affect, may re-mystify research processes and practices. A significant impetus for the development of feminist, postcolonial, queer and anti-racist research methodologies was the need to 
wrestle open the research priorities and practices of the elitist academy. The authority of research, (predominantly white, heterosexual, male and privileged) researchers, and of higher education institutions have historically been shrouded in a kind of epistemological mystification, in which the named, described and categorised are understood through the modalities of those with the authority to name, describe and categorise (see Bhambra, 2014). The explication of research methods and methodology, whilst perhaps lending itself to the incorporation of neoliberal research governance techniques, is also about making clear the ways in which knowledge claims are made. There is a need therefore to engage with ethical questions that centre on the purpose - and politics - of research in the context of neoliberal and global social inequalities; not just neoliberal research governance techniques and its effects on researchers. Indeed surprisingly very little space is afforded within the works that chart this particular emergence of post-qualitative inquiry to the ethics and politics of research in the contexts of increasing global inequalities and colonialism past and present. Instead, neoliberalism is generally described as something producing audit cultures for the research community. For us, urgent questions surrounding the practice of research cannot be separated from increasing global inequalities, an upsurge in militant rightist and racist politics in Europe, Australia and the US, continued gender-based violence and significant challenges for imagining and enacting justice and equity.

Second, and relatedly, given that post-qualitative inquiry does not appear to advocate or suggest a complete retraction from human research, we are concerned that the ethics and politics surrounding the relationship of research, 
its knowledge claims, and 'the researched' are at best muted, or at worst left aside. Representational logics are of course dangerous - research does not simply describe, it is performative: the concepts, categories, descriptions, and languages that we use have effects (cf. Sriprakash \& Mukhopadhyay, 2015). With Tuck and Yang (2014), we think the challenge this poses is how to conduct research that broadens and shifts the view from the Other, to the wider cultural processes, historical practices, and socio-spatial dynamics that create the experiences and categories of 'Otherness'. For them, refusal methodology centres on refusing the categorical objectifying research gaze, which so often leaves aside the wider social and historical relations which have created 'difference', 'disadvantage' and supposed 'dysfunction'. This then, is less a refusal of the possibility - and perhaps political need - to represent the lives of Others, but a call to do so with a view on the often hidden, banal, or unspoken social relations of power.

Within post-qualitative inquiry, we are left wondering what exactly happens to the ethical and political questions and responsibilities that surround research on inequality and the lives of others. In much post-qualitative literature focus is on the researchers and their concerns and deliberations, rather than the relationship between the researcher and the participants of the research, or on the social and political context or repercussions of the research. For instance, discussions of 'exemplar' post-qualitative research in the colonial context of Australia leave aside explication (or direct mention) of the Indigenous people involved in the project, but focus on the non-Indigenous Chief Investigators (see Lather, 2013). Indigenous people are glossed over in the discussions, despite - or 
perhaps because of - an interest in 'collective procedure, a very social enterprise where we start where we are' (ibid, 641). This allows Indigenous people to fall to the margins, whilst the non-Indigenous researchers of the projects are presented as central and powerful. As Spivak (1988: 67-70) critiques in her influential essay, Can the Subaltern Speak?, the Other is presented as monolithic and anonymous and nowhere operative. This functions to create an 'aura of narrative specificity' whilst also working to 'sever theory's link to the signifier'. And as we see in post-qualitative claims of 'collective procedure', 'Intellectuals, however, are named and differentiated' (Spivak 1988: 67).

This can have the result of romanticizing and exoticizing the often challenging research relationships between Indigenous and non-Indigenous (settler) that involve negotiating power and privilege. As Land (2015) notes in her study of activist struggles for Indigenous rights in Australia, solidarity too can be enveloped by the colonial impulse. This can then also gloss over the specific and deep relationship many Indigenous peoples have to land, that generates knowledge and theory (Sium et al 2012: v). The danger is that these accounts may easily slip unwittingly, therefore, into colonizing acts: they marginalize, trivialize, romanticize and exoticize through representation of the 'Other' through a focus on the researcher and her questions, concerns and research objects. Our concern here is that problematic essentialisms have a tendency to creep in when questions of representation are avoided or skimmed. As Spivak (1988: 80) argues, 'a postrepresentationalist vocabulary hides an essentialist agenda'. 
Power in research goes beyond researchers' own struggles. There are also broader concerns about the knowledge we create and to what effect. Postqualitative approaches make assertions about the desire to 'speak back' to (an undefined) neoliberalism. Yet, a reflexive consideration of this speaking back is denied in the focus on troubling of researcher authority. The danger is that the status of the researcher is paradoxically in fact re-mythologised, and reauthorised. If researchers cannot make wise judgements, can we only rely upon affective responses with which to understand Others' experiences? Has affect and intuition entirely replaced method in post-qualitative inquiry, and what are the ethical and political effects of this?

For St Pierre, there is an 'ethical charge' in the 'crisis of representation' posed by new materialism and post-humanism, in that 'we have to think possible worlds in which we might live...' (2013: 655). The 'we', here, is oriented to the academic researcher. It is hard not to interpret this as self-reflexivity folded so tightly back onto itself that it has forgotten that there are other people involved in qualitative (post or not) research. Lather and Pierre posit this ethical charge again in their introductory remarks of a special journal issue on post-qualitative inquiry: 'the ethical charge of our work as inquirers is surely to question our attachments that keep us from thinking and living differently' (2013: 631). We agree that there is an ethical and political challenge for researchers and the academy to think beyond the social reality of neoliberal capitalism. However, this is a project that we do not think is ours alone. We are interested in developing research that takes seriously the role of people in this project, and which critically approaches the 'who' of this 'we' to consider inclusions and exclusions, 
silences and affordances: to understand both the limits and power of 'thinking and living differently' from particular institutional positions.

\section{Conclusion: openings and closures, new and old}

In this 'outsiders' exploration of post-qualitative inquiry we have raised some concerns about colonising histories, power and politics in research. These concerns emerge out of our engagement with the rich possibilities offered by post-qualitative inquiry to unsettle and re-think the increasingly restrictive conditions being tied to what counts as valuable and valid qualitative social research. We suggest first, that the constitution and contingencies of postqualitative inquiry remain mystified through its project of rejecting humanism. These boundary politics, we argue, may inadvertently obfuscate consideration of the place of post-qualitative inquiry within a much wider geo-political context of research work and the academy. Second, we propose that the post-qualitative heralding of the 'new' mobilises a problematic temporal logic of (modernistcolonial) progress, which relies on particular interpretations (and arguably caricatures) of humanism. Such a focus on the 'new' can gloss over the need for deep historical engagement in a research agenda concerned with the operations of power. Third, we have examined the ways in which the ethical and political dimensions of research are insufficiently attended to in the post-qualitative research discourse. We suggest that post-qualitative inquiry tends to interpret ethical and political concerns in relation to the researcher, and not in relation to the political dimensions of research knowledge and practice. 
These critical reflections are offered in the context of continuing challenges within the academy to generate approaches to research that engage and challenge ongoing global inequalities, suffering, and oppression. At the heart of our discussion is a concern that post-qualitative inquiry may unwittingly remystify research in its attempt to critically defy neoliberal accountability and transparency agendas. The post-qualitative problematization of interviews, transcripts, data, methodology, coding, and so on, may re-iterate the colonial and masculine 'knowing' researcher, who is not required to demonstrate how they came to 'understand'; instead, they 'glean', 'feel' and 'sense' their 'data'. In other words, the post-humanist problematization of data has not led post-qualitative inquiry to stop researching people and reporting on this research. The question still remains, then, what are the political and ethical dimensions and responsibilities on the reporting of these experiences?: a particularly important question when considering the continuing effects of colonial inequality and injustice, both within and beyond the academy.

This is not to deny the importance of, or possibility offered by, many of the conceptual and methodological tools taken up by post-qualitative inquiry. Certainly, for instance, refusal politics and methodologies have offered powerful and productive means to reveal the limits of dominant discourse and power. For example, writing outside the post-qualitative domain and from within Indigenous studies, Audra Simpson's (2014) methodological and conceptual advancement of refusal demonstrates how Indigenous politics of refusal can trouble the taken-for-granted presumptions that rest within the settler colonial state, as well as the erasures of Indigeneity that can occur in proclamations of 
'inclusion' within the settler state. In this research, refusal faces the messy politics of representation, and 'voice', by working conceptually with refusal in the context of a history of state refusal for Indigenous peoples. Refusal, in this sense, becomes concerned with connecting Indigenous people's refusal to accept the supposed 'settlement' of the colonial state with, as Audra Simpson puts it, the "shifting historical context of the present" (2007: 78). This sort of work alerts us to the spaces that are left largely unattended within the emergent postqualitative inquiry field. We wonder, therefore, whether there is greater value in seeking ways for research to connect, or at the very least, to methodologically and conceptually deploy refusal in ways that face more directly the politics of research.

This is a defence of politically attentive research agendas in one sense, but also a commitment to addressing multiple relations of power in knowledge production within and through research. As postcolonial sociologist Gurminder Bhambra suggests, there is methodological value in 'identifying and explicating the connections that enable understandings always to be more expansive than the identities or events they are seeking to explain' (2014: 156). She goes on to quote Holmwood and Stewart (1991: 61), 'the important point is not to reify the new explanation, but to indicate how it was produced by turning towards explanatory problems, rather than away from them, and creating new understandings and resources in their solution'. Indeed, the promise of something 'new' is central to the critical projects of de- and re- construction in the 'posts', whether post-qualitative or postcolonial. However, reading the postqualitative literature from a postcolonial lens, we are concerned with the 
(unintended) reification of a number of binaries (e.g. new/old,

flatness/hierarchy, openness/closed, non-representational/representation, ontology/epistemology, affect/language). Again, drawing on Bhambra, we consider whether the task at hand is 'not a puncturing of meaning, but of hierarchy, and a call to reconstruct meaning and to engage in new collaborative endeavours' (Bhambra, 2014: 156). Without explicit attention to power and history, the (non)representational logics of post-qualitative inquiry risk operating less as 'new' mechanisms for generative and subversive post-humanist research and more as processes of closure and erasure: closed-off from the worlds and people being researched, whose histories and voices are obfuscated, displaced and, at worst, erased.

\section{References}

Ahmed, S. (2008) Some preliminary remarks on the founding gestures of the 'new materialism', European Journal of Women's Studies 15:1, 23-39.

Bhambra, G. (2014) Connected Sociologies. London: Bloomsbury Publishing.

Bridges-Rhoads, S. (2015) Writing paralysis in (post) qualitative research, Qualitative Inquiry 21:8, 704-10.

Brown, W. (2015) Undoing the Demos: Neoliberalism's Stealth Revolution, Brooklyn, New York: Zone Books.

Canagarajah, S. (2002) The Geopolitics of Academic Writing. Pittsburgh: University of Pittsburgh Press. 
Connell, R.W. (2007) Southern Theory: The Global Dynamics of Knowledge in Social Science, Sydney: Allen and Unwin.

Davies, B., de Shauwer, E., Claes, L., de Munck, K., van de Putte, I. \& Verstichele, M. (2013) Recognition and difference: a collective biography, International Journal of Qualitative Studies in Education 26:6, 680-691.

Farrugia, D. \& Gerrard, J. (2016) Academic knowledge and contemporary poverty: the politics of homelessness research. Sociology, 50:2, 267-284

Fanon, F. (1966) The Wretched of the Earth, New York: Grove Press, Inc.

Foucault, M. (1994) Michel Foucault: Power, London: Penguin.

Greene, J.C. (2013) On rhizomes, lines of flight, mangles, and other assemblages, International Journal of Qualitative Studies in Education 26:6, 749-758.

Hall, S. (1996) 'The meaning of New Times', in D. Morley \& K. Chen (eds.) Stuart Hall: Critical Dialogues in Cultural Studies, pp 223-237, London \& New York:

Honan, E. (2014) Disrupting the habit of interviewing, Reconceptualizing Educational Research Methodology 5:1, 1-17.

Jackson, A. Y. (2013) Posthumanist data analysis of mangling practices, International Journal of Qualitative Studies in Education 26:6, 741-748

Land, C. (2015) Decolonizing Solidarity: Dilemmas and Directions for Supporters of Indigenous Struggles, London: Zed Books.

Lather, P. (2013) Methodology-21: what do we do in the afterward? International Journal of Qualitative Studies in Education 26:6, 634-645. 
Lather, P. (2001) Postbook: working the ruins of feminist ethnography, Signs $27: 1,199-277$.

Lather, P. \& Smithies, C. (1997) Troubling the Angles: Women Living with HIV/AIDS. Boulder, Colo: WestviewPress

Lather, P. \& St. Pierre, E. A. (2013) Post-qualitative inquiry, International Journal of Qualitative Studies in Education 26:6, 629-633.

Mazzei, L. A. (2013) A voice without organs: interviewing in posthumanist research, International Journal of Qualitative Studies in Education 26:6, 732740.

MacLure, M. (2013) Researching without representation? Language and materiality in post-qualitative methodology, International Journal of Qualitative Studies in Education 26:6, 658-667.

Moreton-Robinson, A. (2015) The White Possessive: Property, Power, and Indigenous Sovereignty, Minneapolis, London: University of Minnesota Press.

Moreton-Robinson, A. (ed.) (2011) Whitening Race: Essays in Social and Cultural Criticism. Canberra: Aboriginal Studies Press.

Peel, M. (2003) The Lowest Rung: Voices of Australian Poverty. Cambridge: Cambridge University Press.

Pederson, H. (2013) Follow the Judas sheep: materializing post-qualitative methodology in zooethnography space, International Journal of Qualitative Studies in Education 26:6, 717-731. 
Reay, D. (2015) Academic Viagra: tying Kate Middleton up in knots, British Journal of Sociology of Education 36:5, 798-801.

Said, E. (1983). The World, the Text and the Critic. Cambridge, Massachusetts: Harvard University Press.

Said, E.W. (2004) Humanism and Democratic Criticism. Basingstoke: Palgrave.

Sherwood, M. (2001) Race, empire and education: teaching racism, Race and Class 42(3): 1-28.

Simpson, A. (2014) Mohawk Interruptus: Political Life Across the Borders of Settler States. Durham \& London: Duke University Press.

Simpson, A. (2007) On ethnographic refusal: indigeneity, 'voice' and colonial citizenship. Junctions 9: 67-80.

Simpson, M. K. (2007) From savage to citizen: education, colonialism and idiocy, British Journal of Sociology of Education 28(5): 561-574.

Sium, A., Desai, C. \& Ritskes, E. (2012) Towards the 'tangible unknown': Decolonization and the Indigenous future, Decolonization: Indigeneity, Education \& Society, 1(1): i-xiii.

Smith, L. T. (2012). Decolonizing Methodologies: Research and Indigenous Peoples (2nd Edition), London: Zed Books.

Spivak, G. C. (1988) 'Can the subaltern speak?', in C. Nelson \& L. Grossberg (eds.) Marxism and the Interpretation of Culture, pp 271-313, Bassingstoke: Macmillan Education. 
Sriprakash, A. \& Mukhopadhyay, R. (2015) Reflexivity and the politics of knowledge: educational researchers as 'brokers' and 'translators' of international development, Comparative Education 51(2): 231-246.

St Pierre, E. A. (2014) A brief and personal history of post qualitative research: toward "post inquiry", Journal of Curriculum Theorizing 30(2): 2-19.

St Pierre, E. A. (2013) The Appearance of Data. Cultural Studies Critical Methodologies. 13(3): 223-227.

St Pierre, E. A. (2013) The posts continue: becoming. International Journal of Qualitative Studies in Education 26(6): 646-657.

St Pierre, E. A. (2008) Decentering voice in qualitative inquiry, International Review of Qualitative Research 1(3): 319-33.

St Pierre, E. A. \& Pillow, W. S. (2000) 'Introduction: inquiry among the ruins', in E. A. St Pierre \& W. S. Pillow (eds.) Working the Ruins: Feminist Poststructural Theory and Methods in Education, pp. 1-24, London: Routledge.

Stoler, A. L. (2008) Imperial debris: reflections on ruins and ruination, Cultural Anthropology 23(2): 191-219.

Thrift, N. (2008) Non-representational theory: space, politics, affect, London \& New York: Routledge.

Tuck, E. \& McKenzie, M. (2015) Relational validity and the "where" of inquiry place and land in qualitative research, Qualitative Inquiry, 1-6 (iFirst).

Tuck, E., \& Yang, K. W. (2014) Unbecoming claims: pedagogies of refusal in qualitative research, Qualitative Inquiry 20(6): 811-818. 